\title{
IMPLEMENTASI ACTIVITY BASED COSTING TERHADAP PERHITUNGAN BIAYA OPERASIONAL PADA UNIT LAYANAN RUMAH SAKIT X SURABAYA
}

\author{
Annisa Rahmawati \\ Universitas 45 Surabaya \\ (rahmawaty.annisa@gmail.com)* \\ Achmad Daengs GS \\ Universitas 45 Surabaya \\ (adaengsgs@univ45sby.ac.id)
}

Disubmit: 22 Januari 2021

Mulai Review: 30 Maret 2021

Selesai Review: 28 April 2021

Diterima: 29 April 2021

\begin{abstract}
Hospital is an institution that is in the realm of non-profit, where its main activities consist of medical activities, health services, and health education. During its development, hospital activities shifted to the business realm where apart from providing health services, the hospital also focused its activities as a business entity. This research was conducted at $X$ Hospital, located in West Surabaya. In carrying out its economic activities, Hospital X charges its operational costs using a simple method. The research method used is descriptive qualitative method, which produces descriptive data from observations, interviews and primary data from the object under study. The research results show that the charging of operational costs with the Activity Based Costing method provides a more accurate and reasonable calculation of loading so that the results of these calculations can be used to compile financial reports with fair value and can be useful as a basis for calculations in order to determine service rates provided to the Hospital X.
\end{abstract}

Key Word: Cost, Activity Based Costing, Hospital

\begin{abstract}
Abstrak
Rumah Sakit adalah lembaga yang berada pada ranah nirlaba, dimana kegiatan utamanya terdiri dari kegiatan pengobatan, layanan kesehatan, dan penyuluhan mengenai Kesehatan. Dalam perkembangannya, kegiatan Rumah Sakit bergeser pada ranah bisnis dimana selain memberikan layanan Kesehatan, Rumah Sakit juga memfokuskan kegiatannya sebagai badan usaha. Penelitian ini dilakukan di Rumah Sakit X yang berlokasi di Surabaya barat. Dalam pelaksanaan kegiatan ekonominya, Rumah Sakit $\mathrm{X}$ membebankan biaya operasionalnya dengan metode yang sederhana. Metode penelitian yang digunakan adalah metode kualitatif deskriptif, yang menghasilkan data deskriptif dari observasi, wawancara serta data primer dari object yang diteliti. Hasil penelitian memaparkan bahwa pembebanan biaya operasional dengan metode Activity Based Costing memberikan perhitungan pembebanan yang lebih akurat dan wajar sehingga hasil perhitungan tersebut dapat dipergunakan untuk menyusun laporan keuangan dengan nilai yang wajar serta dapat berguna sebagai dasar untuk perhitungan dalam rangka menentukan tarif layanan yang diberikan pada Rumah Sakit X.
\end{abstract}

Kata Kunci: Biaya, Activity Based Costing, Rumah Sakit 


\section{PENDAHULUAN}

Biaya dapat dirujuk sebagai sesuatu yang meningkat, ketika aktivitas yang terjadi berjumlah lebih banyak, dan menurun ketika jumlah aktivitas juga mengalami penurunan, dimana biaya terbagi menjadi dua jenis yaitu biaya tetap dan biaya variable. (Banker \& Byzalov, 2014; Weiss, 2010). Activity Based Costing merupakan sistem perhitungan biaya yang melakukan penelusuran biaya terhadap aktivitas yang menyebabkan terjadinya aktivitas tersebut dan membebankan biaya aktivitas tersebut kepada produk. System perhitungan biaya dengan menggunakan Activity Based Costing dapat meningkatkan akurasi alokasi biaya tidak langsung dengan mengaitkan setiap biaya yang terjadi dengan aktivitas yang menyebabkan aktivitas tersebut (Caroline \& Wokas, 2016).

Rumah sakit ialah organisasi nirlaba yang dahulu didirikan oleh Lembaga pemerintah atau lembaga sosial, yang bergerak dalam bidang layanan Kesehatan yang bertanggung jawab untuk melaksanakan kegiatan pengobatan yang didalamnya termasuk kegiatan perawatan, dimana kegiatan tersebut dimaksudkan untuk menyembuhkan pasien yang sakit, serta memberikan penyuluhan mengenai tata cara hidup sehat khususnya kepada masyarakat awam. Seiring dengan berjalannya waktu, lembaga swasta juga membangun rumah sakit dengan fungsi yang sama yaitu memberikan layanan di bidang kesehatan. Dengan adanya kondisi tersebut, maka hal ini juga menggeser bentuk dari organisasi rumah sakit, yang tadinya merupakan organisasi nirlaba menjadi organisasi yang berorientasi pada kegiatan ekonomi, dimana kegiatan layanan kesehatannya di fokuskan sebagai badan usaha yang mencari laba (Natalia, Mendur, Sarayar, \& Emergency, 2016).

Rumah Sakit X adalah Rumah Sakit Swasta yang berada di Surabaya Barat. Rumah Sakit X telah berupaya untuk memberikan pelayanan optimal kepada para pasien dengan tarif layanan Kesehatan yang terjangkau. Pada saat melakukan perhitungan biaya pelayanan, ada rumah sakit mengalami kesulitan karena informasi yang berkaitan dengabn perhitungan biaya yang tersedia tidak lengkap, dan perhitungan pembebanan biaya hanya dilakukan dengan perkiraan yang dirasa pantas. Dimana kesulitan tersebut berpengaruh terhadap pembebanan biaya pelayanan rumah sakit yang pada akhirnya berdampak terhadap penentuan harga jual layanan. Kendala yang dihadapi oleh Rumah Sakit tersebut bersumber pada penentuan pembebanan biaya atas pemanfaatan sarana dan prasarana yang menunjang aktifitas layanan Kesehatan yang diberikan, yang terdiri dari penggunaan alat penunjang medis dan obat obatan, serta pembebanan biaya pada penggunaan tenaga kerja. Oleh karenanya metode perhitungan biaya Activity Based Costing dirasa cocok untuk digunakan dalam menghitung pembebanan biaya operasional pada Rumah Sakit ini agar didapatkan perhitungan biaya yang tepat berdasarkan aktivitas, sehingga pihak Rumah Sakit dapat menentukan biaya layanan yang akan dibebankan pada pasien yang datang ke Rumah Sakit tersebut.

Beberapa penelitian terdahulu yang menjadi rujukan dari penelitian ini diantaranya :

1. Harmana (2020). Penelitian ini dilaksanakan di Rumah Sakit Abdi Medik Tabanan. Pada saat memperhitungkan biaya layanan kesehatan, Rumah Sakit Abdi Medik Tabanan, menggunakan metode perhitungan tradisional yang hanya menggunakan satu Cost Driver saja sebagai dasar pembebanan biaya layanan kesehatan. Penentuan tarif jasa rawat inap merupakan komponen penting, karena akan berpengaruh terhadap kemampuan rumah sakit untuk mendapatkan laba. Penelitian ini dilakukan dengan tujuan untuk mengetahui imbas dari implementasi metode Activity Based Costing dalam menentukan besarnya tarif jasa rawat inap pada Rumah Sakit Abdi Medik Tabanan. Hasil perhitungan tarif rawat inap dengan menggunakan metode Activity Based Costing 
ternyata memaparkan perhitungan penentuan tarif rawat inap yang lebih akurat mulai dari tarif untuk kelas VIP sampai dengan tarif kelas 3 (Harmana \& Accounting, 2020).

2. Penelitian yang dilakukan oleh Yemimaria (2018). Penelitian tersebut mengobservasi penerapan tarif yang di implementasikan di unit layanan Rumah Sakit Pupuk Kaltim Siaga Ramania Samarinda, yang terdiri dari layanan rawat inap kelas VVIP VIP Kelas I, II, dan III, rawat jalan, layanan rawat darurat, poli umum dan spesialisasi, layanan laboratorium, layanan MSCT, layanan instalasi farmasi dan radiologi. Rumah Sakit tersebut masih menggunakan system perhitungan tradisional dalam pembebanan biaya untuk setiap layanannya, dimana hal tersebut dapat memicu terjadinya distorsi biaya layanan dan berdampak pada penetapan tarif layanan yang tidak akurat. Kelemahan sistem penetapan tarif tradisional tersebut dapat disempurnakan melalui implementasi sistem pembebanan tarif yang didasarkan pada aktivitas yang disebut dengan metode Activity Based Costing $(A B C)$. Metode tersebut menggunakan aktivitas sebagai tumpuan penggolongan biaya untuk menghasilkan informasi activity cost dan informasi biaya produk yang akurat, sehingga Activity Based Costing dapat menjadi metode yang sesuai untuk di implementasikan pada unit usaha yang memiliki lini produk layanan yang beragam sebagaimana yang dimiliki oleh Rumah Sakit (Yemimaria, Utary, \& Subhan, 2018).

3. Penelitian yang dilakukan oleh Damayanti (2017). Penelitian tersebut mengobservasi penetapan tarif yang terapkan pada Hotel Amaris Kota Madiun yang terbagi menjadi tiga jenis kamar berdasarkan tingkatan harganya. Pada prakteknya, penetapan harga layanan kamar hanya didasarkan pada layanan yang diberikan saja tanpa memperhitungkan biaya overhead dan biaya tidak langsung yang juga turut menjadi pemicu biaya dalam komponen pembebanan biaya layanan. Penggunaan metode Activity Based Costing ( $A B C$ ), dalam perhitungan pembebanan biaya layanan hotel dapat memberikan paparan perhitungan pembebanan biaya yang lebih akurat karena, metode tersebut menggunakan aktivitas sebagai dasar pengelompokan biaya untuk menghasilkan informasi activity cost dan informasi biaya produk yang akurat (Damayanti, Murwani, \& Utomo, 2017).

Secara garis besar biaya terbagi menjadi dua jenis yaitu, biaya tetap dan biaya variable yang didasarkan pada jumlah penjualan yang terjadi atau pemicu aktivitas lainnya. Meskipun biaya tetap dan biaya variable seringkali diinterpretasikan sebagai bagian fundamental dari perilaku biaya, tetapi biaya tersebut disebabkan oleh dua sumber aktivitas yang berbeda, yang dapat dengan mudah disesuaikan dalam jangka pendek. Sumber aktivitas yang bersifat tetap seperti misalnya aktivitas yang berasal dari Gedung dan peralatan utama lainnya, merupakan sumber aktivitas yang tidak dapat dirubah dalam jangka pendek. Oleh karenanya biaya tersebut akan memiliki besaran yang sama samai dengan permintaan actual diketahui, yang dapat menyebabkan biaya tetap tersebut meningkat seiring dengan jumlah penjualan yang terealisasi. Sedangkan sumber biaya variable, biasanya disebabkan oleh aktivitas yang berasal dari bahan baku langsung atau bahan baku tidak langsung, dimana hal tersebut dapat disesuaikan dalam jangka pendek. Oleh karenanya, sumberdaya tersebut digunakan berdasarkan kebutuhan atas permintaan actual yang pada akhirnya menyebabkan biaya variable. Model tradisional mengimplikasikan hubungan mekanis antara penjualan dan biaya, dimana biaya tetap merupakan biaya yang telah ditentukan sebelumnya dan biaya variable mencerminkan biaya ang timbul dari penggunaan sumber daya variable yang besaran penggunaannya menyesuaikan dengan penjualan yang terjadi (Banker \& Byzalov, 2014). 
Activity Based Costing merupakan system perhitungan biaya yang melakukan penelusuran biaya terhadap aktivitas yang menyebabkan terjadinya aktivitas tersebut (Cost Driver) dan membebankan biaya aktivitas tersebut kepada produk. System perhitungan biaya dengan menggunakan Activity Based Costing dapat meningkatkan akurasi alokasi biaya tidak langsung dengan mengaitkan setiap biaya yang terjadi dengan aktivitas yang menyebabkan aktivitas tersebut (Caroline \& Wokas, 2016).

Didalam metode perhitungan Activity Based Costing terdapat istilah penting yang disebut Cost Driver. Cost Driver merupakan dasar pengalokasian biaya yang digunakan dalam metode Activity Based Costing yang merupakan dasar penentu besaran usaha dan beban kerja yang diperlukan untuk melakukan sebuah kegiatan. Adapun perhitungan Cost Driver per unit dapat dihitung dengan menggunakan rumus berikut ini :

$$
\text { Tarif Per Unit Cost Driver }=\frac{\text { Jumlah Aktivitas }}{\text { Cost Driver }}
$$

(Anwar \& Barus, 2019; Panekenan \& Sabijono, 2014)

Tahapan yang dilakukan dalam perhitungan biaya menggunakan system Activity Based Costing adalah sebagai berikut

1. Melakukan identifikasi terhadap sumber daya dan aktivitas yang akan dilakukan. Tahapan ini terdiri dari aktivitas berikut ini :

a. Aktivitas yang berada pada tingkat unit merupakan aktivitas yang dijalankan untuk memproduksi satu unit produk atau layanan

b. Aktivitas yang berada pada tingkat kelompok merupakan aktivitas yang dijalankan untuk memproduksi setiap batch produk atau layanan

c. Aktivitas yang berada pada tingkat produk merupakan aktivitas yang dijalankan untuk menopang proses produksi pada lini produk atau layanan yang berbeda

d. Aktivitas yang berada pada tingkat fasilitas merupakan aktivitas yang dijalankan untuk menopang produksi produk atau layanan secara umum

2. Membebankan biaya yang terjadi terhadap sumber aktivitas

Aktivitas ini melibatkan perhitungan biaya yang didasarkan pada aktivitas yang menggunakan cost driver atas sumberdaya yang dikonsumsi terhadap pembebanan biaya sumber daya terhadap aktivitas.

3. Membebankan biaya aktivitas terhadap object biaya

Tahapan terakhir ini merupakan tahapan untuk membebankan biaya aktivitas terhadap object biaya yang didasarkan pada cost driver untuk konsumsi aktivitas yang tepat

(Pawiyataningrum, 2014)

Dalam pelaksanaan perhitungan biaya, system perhitungan biaya Activity Based Costing terdiri dari beberapa Hierarki Biaya yang didasarkan pada pemicu biaya (cost driver) diantaranya 
1. Output Unit Level Cost. Merupakan satuan biaya yang digunakan secara langsung untuk memproduksi output produk atau output layanan. Biaya ini berbanding lurus dengan jumlah unit produk atau layanan yang di produksi

2. Batch Level Cost. Merupakan satuan biaya yang digunakan dalam produksi output produk atau output layanan yang didasarkan pada jumlah batch produksi, tanpa memperhatikan jumlah output atau layanan yang diproduksi dalam setiap batch.

Product (or Services) Sustaining Cost. Merupakan satuan biaya yang digunakan dalam produksi output yang spesifik, dan umumnya dikerjakan tanpa melihat besaran jumlah batch atau besaran jumlah unit yang diproduksi.

3. Facility Sustaining Cost. Merupakan satuan biaya yang digunakan dalam aktivitas produksi, dimana aktivitas tersebut tidak dapat ditelusuri secara langsung terhadap satuan output produk atau layanan secara individual.

(Anwar \& Barus, 2019; Kapojos, Sondakh, \& Waladouw, 2014; Rotikan, 2013)

\section{METODE PENELITIAN}

Penelitian ini dilakukan dengan metode kualitatif deskriptif yang merupakan jenis penelitian yang dimaksudkan untuk menganalisa suatu kejadian atau fenomena, dimana penelitian jenis ini dilakukan dengan observasi, wawancara, dan dokumentasi (Gunawan, 2013; Sendari, 2019). Penelitian ini dilakukan di Rumah Sakit X yang merupakan Rumah Sakit Swasta yang berlokasi di Surabaya Barat. Adapun data yang digunakan dalam penelitian ini adalah data primer yang berasal dari daftar pembebanan biaya dan data perhitungan pembebanan biaya operasional dari Rumah Sakit yang bersangkutan.

\section{HASIL DAN PEMBAHASAN}

Rumah Sakit X merupakan Rumah Sakit yang beroperasi di Surabaya Barat. Rumah Sakit ini menjalankan layanan Kesehatan yang terdiri dari layanan rawat jalan, poli spesialis bedah umum, poli bedah plastic, poli spesialis anak, poli fisioterapi, poli spesialis penyakit dalam, poli spesialis jantung dan pembuluh darah, poli onkologi, poli spesialis syaraf, poli umum, layanan laboratorium, layanan radiologi, layanan farmasi, layanan rehabilitasi medik, layanan rawat inap, layanan operasi, layanan instalasi gawat darurat (IGD). Berdasarkan hasil penelitian, beban aktivitas yang terjadi dalam penyelenggaraan kegiatan Rumah Sakit X terdiri dari :

\begin{tabular}{cll}
\hline & & \multicolumn{2}{c}{ Tabel 1 } \\
& & \\
Da & \multicolumn{1}{c}{ Beban Layanan } & Beban Umum dan Administrasi \\
\hline $\mathbf{1}$ & Beban Pemakaian Bahan Obat Obatan & Beban Gaji Karyawan \\
\hline $\mathbf{2}$ & Beban Jasa Medis Dokter & Beban Listrik Air Telepon \\
\hline $\mathbf{3}$ & Beban Tenaga Perawat & Beban Transportasi \\
\hline $\mathbf{4}$ & Beban MRI & Beban Tes dan Pendidikan Karyawan \\
\hline $\mathbf{5}$ & Beban Rujukan Laboratorium & Beban Promosi \\
\hline $\mathbf{6}$ & Beban Pemakaian Alat Operasi & Beban ATK dan Fotocopy \\
\hline $\mathbf{7}$ & Beban Sterilisasi Alat & Beban Keperluan Kantor \\
\hline
\end{tabular}




\begin{tabular}{cll}
\hline $\mathbf{8}$ & $\begin{array}{l}\text { Beban Kantung Darah dan Gas Medik } \\
\text { (Bagi pasien yang menjalani tindakan } \\
\text { operasi) }\end{array}$ & Beban Rumah Tangga \\
\hline $\mathbf{9}$ & Beban Konsumsi Pasien & Beban Perizinan dan Notaris \\
\hline $\mathbf{1 0}$ & Beban Lain Lain & Beban Tenaga Outsourcing \\
\hline $\mathbf{1 1}$ & Beban Pemeliharaan \\
\hline $\mathbf{1 2}$ & Beban Penyusutan \\
\hline $\mathbf{1 3}$ & Beban Asuransi \\
\hline $\mathbf{1 4}$ & Beban Pajak \\
\hline $\mathbf{1 5}$ & Beban Administrasi Bank \\
\hline $\mathbf{1 6}$ & Beban Lain Lain \\
\hline
\end{tabular}

Sumber : Data Primer 
Beban Operasional yang terjadi di Rumah Sakit X terdiri dari Beban Layanan dan Beban Administrasi dan Umum. Paparan data Beban Operasional yang terjadi di Rumah Sakit X pada tahun 2019 dan 2018 adalah sebagai berikut :

\begin{tabular}{|c|c|c|c|c|c|c|c|c|c|}
\hline \multicolumn{10}{|c|}{$\begin{array}{c}\text { TABEL } 2 \\
\text { RINCIAN BEBAN LAYANAN RUMAH SAKIT X TAHUN } 2019 \\
\end{array}$} \\
\hline Keterangan & Total & Rawat Jalan & IGD & Rawat Inap & Instalasi Bedah & Farmasi & Laboratorium & Radiologi & Rehab Medis \\
\hline Pemakaian Bahan & 6.006 .428 .161 & - & - & - & 2.519 .583 .876 & 3.376 .651 .121 & 110.193 .165 & - & - \\
\hline Jasa Medis Dokter & 6.311 .754 .593 & 1.277 .468 .400 & 42.881 .000 & 572.647 .242 & 3.272 .096 .840 & - & 126.980 .162 & 386.852 .350 & 632.828 .600 \\
\hline Jasa Perawat & 23.332 .500 & - & - & - & 23.332 .500 & - & - & - & - \\
\hline Beban MRI & 93.520 .532 & - & - & - & - & - & - & 93.520 .532 & - \\
\hline Rujukan Laborarium & 65.444 .215 & - & - & - & - & - & 65.444 .215 & - & - \\
\hline Pemakaian Alat & 122.299 .650 & - & - & - & 122.299 .650 & - & - & - & - \\
\hline Beban Steril Alat & 45.310 .000 & - & - & - & 45.310 .000 & - & - & - & - \\
\hline Darah \& Gas Medik & 61.729 .000 & - & - & - & 61.729 .000 & - & - & - & - \\
\hline Makan Pasien & 125.524 .200 & - & - & 125.524 .200 & - & - & - & - & - \\
\hline Beban Lainnya & 106.198 .286 & 26.549 .572 & 26.549 .572 & 26.549 .572 & 26.549 .572 & - & - & - & - \\
\hline Totan Beban Layanan & 12.961.541.137 & 1.304 .017 .972 & 69.430 .572 & 724.721 .013 & 6.070.901.437 & 3.376 .651 .121 & 302.617 .541 & 480.372 .882 & 632.828 .600 \\
\hline
\end{tabular}

Sumber : Data Primer 


\begin{tabular}{|c|c|c|c|c|c|c|c|c|c|}
\hline \multicolumn{10}{|c|}{$\begin{array}{c}\text { TABEL } 3 \\
\text { BEBAN ADMINISTRASI \& UMUM RUMAH SAKIT X TAHUN } 2019\end{array}$} \\
\hline Keterangan & Total & Rawat Jalan & IGD & Rawat Inap & Instalasi Bedah & Farmasi & Laboratorium & Radiologi & Rehab Medis \\
\hline Beban Karyawan & 4.380 .536 .240 & 561.037 .897 & 564.629 .103 & 757.670 .354 & 605.560 .215 & 490.258 .474 & 469.064 .729 & 454.634 .433 & 477.681 .035 \\
\hline Beban Alat & 570.306 .903 & 88.874 .849 & 39.044 .340 & 172.620 .613 & 122.790 .104 & 36.744 .249 & 36.744 .249 & 36.744 .249 & 36.744 .249 \\
\hline Beban Transportasi & 21.514 .236 & 2.689 .280 & 2.689 .280 & 2.689 .280 & 2.689 .280 & 2.689 .280 & 2.689 .280 & 2.689 .280 & 2.689 .280 \\
\hline Beban Tes \& Pendidikan Keryawan & 168.405 .311 & 18.595 .664 & 18.795 .664 & 26.195 .664 & 18.820 .664 & 28.920 .664 & 18.595 .664 & 18.595 .664 & 19.885 .664 \\
\hline Beban ATK, Foto Copy & 134.727 .566 & 16.840 .946 & 16.840 .946 & 16.840 .946 & 16.840 .946 & 16.840 .946 & 16.840 .946 & 16.840 .946 & 16.840 .946 \\
\hline Beban Keperluan Kantor & 10.124 .100 & 726.138 & 686.138 & 2.865 .638 & 1.226 .138 & 686.138 & 991.638 & 686.138 & 2.256 .138 \\
\hline Beban Rumah Tangga & 245.980 .568 & 21.083 .888 & 21.083 .888 & 24.276 .388 & 98.393 .353 & 20.285 .763 & 20.285 .763 & 20.285 .763 & 20.285 .763 \\
\hline Beban Perjalanan Dinas & 11.732 .336 & 1.257 .792 & 1.307 .792 & 1.657 .792 & 1.257 .792 & 1.257 .792 & 1.257 .792 & 2.107 .792 & 1.627 .792 \\
\hline Beban Perijinan \& Notaris & 48.644 .000 & 1.125 .000 & 1.125 .000 & 1.209 .000 & 5.164 .000 & 922.500 & 922.500 & 37.262 .500 & 913.500 \\
\hline Beban Outsoursing & 613.895 .519 & 76.736 .940 & 76.736 .940 & 76.736 .940 & 76.736 .940 & 76.736 .940 & 76.736 .940 & 76.736 .940 & 76.736 .940 \\
\hline Beban Pemeliharaan & 208.388 .885 & 16.636 .360 & 16.636 .360 & 26.103 .323 & 87.726 .618 & 14.269 .619 & 14.269 .619 & 14.269 .619 & 18.477 .369 \\
\hline Beban Penyusutan & 3.696 .045 .996 & 253.201 .651 & 430.327 .050 & 470.881 .007 & 1.147 .267 .430 & 228.458 .667 & 223.335 .926 & 631.271 .397 & 311.302 .868 \\
\hline Beban Asuransi & 25.205 .150 & 2.845 .579 & 2.845 .579 & 7.726 .609 & 5.286 .094 & 1.625 .322 & 1.625 .322 & 1.625 .322 & 1.625 .322 \\
\hline Beban Pajak & 103.699 .315 & 12.612 .861 & 12.612 .861 & 20.331 .711 & 16.472 .286 & 9.783 .149 & 9.783 .149 & 9.783 .149 & 12.320 .149 \\
\hline Beban Admin Bank & 212.669 .251 & 26.583 .656 & 26.583 .656 & 26.583 .656 & 26.583 .656 & 26.583 .656 & 26.583 .656 & 26.583 .656 & 26.583 .656 \\
\hline Beban Lain - lain & 47.396 .498 & 5.110 .705 & 5.110 .705 & 11.220 .789 & 5.511 .481 & 5.110 .705 & 5.110 .705 & 5.110 .705 & 5.110 .705 \\
\hline Total Beban Administrasi \& Umum & 10.644 .453 .250 & 1.124 .106 .877 & 1.255 .202 .973 & 1.663 .757 .381 & 2.256 .474 .668 & 979.321.534 & 942.985 .548 & 1.373 .375 .223 & 1.049 .229 .046 \\
\hline
\end{tabular}

Sumber : Data Primer 
TABEL 4

\begin{tabular}{|c|c|c|c|c|c|c|c|c|c|}
\hline Uraian & Total & Rawat Jalan & IGD & Ranap & Instalasi Bedah & Farmasi & Laboratorium & Radiologi & Rehab Medis \\
\hline Pemakaian Bahan & 7.094 .589 .056 & - & - & - & 2.989 .215 .739 & 3.824 .598 .164 & 136.766 .353 & 144.008 .800 & - \\
\hline Jasa Medis Dokter & 7.024 .863 .483 & 1.396 .354 .400 & 46.075 .500 & 685.886 .494 & 3.695 .560 .600 & - & 145.097 .065 & 390.272 .250 & 665.617 .175 \\
\hline Jasa Perawat & 128.596 .000 & - & - & - & 128.596 .000 & - & - & - & - \\
\hline Beban MRI & 212.151 .547 & - & - & - & - & - & 17.111 .528 & 195.040 .019 & - \\
\hline Rujukan Laborarium & 62.892 .354 & - & - & - & - & - & 62.892 .354 & - & - \\
\hline Pemakaian Alat & 109.500 .000 & - & - & - & 109.500 .000 & - & - & - & - \\
\hline Beban Steril Alat & 20.800 .000 & - & - & - & 20.800 .000 & - & - & - & - \\
\hline Darah \& Gas Medik & 70.740 .500 & - & - & - & 70.740 .500 & - & - & - & - \\
\hline Makan Pasien & 143.504 .000 & - & - & 143.504 .000 & - & - & - & - & - \\
\hline Beban Lainnya & 111.242 .718 & 27.810 .680 & 27.810 .680 & 27.810 .680 & 27.810 .680 & - & - & - & - \\
\hline Totan Beban Pelayanan & 14.978 .879 .658 & 1.424 .165 .080 & 73.886.180 & 857.201 .173 & 7.042.223.518 & 3.824.598.164 & 361.867 .300 & 729.321 .069 & 665.617.175 \\
\hline
\end{tabular}

Sumber : Data Primer 


\begin{tabular}{|c|c|c|c|c|c|c|c|c|c|}
\hline \multicolumn{10}{|c|}{$\begin{array}{c}\text { TABEL } 5 \\
\text { BEBAN ADMINISTRASI \& UMUM TAHUN } 2018\end{array}$} \\
\hline Uraian & Total & Rawat Jalan & IGD & Ranap & Instalasi Bedah & Farmasi & Laboratorium & Radiologi & Rehab Medis \\
\hline Beban Karyawan & 4.140 .048 .482 & 599.883 .931 & 467.517 .698 & 660.510 .177 & 592.762 .772 & 511.804 .105 & 446.704 .957 & 448.920 .916 & 411.943 .923 \\
\hline Beban Alat & 741.860 .570 & 124.103 .108 & 50.510 .926 & 220.991 .381 & 156.399 .199 & 47.463 .989 & 47.463 .989 & 47.463 .989 & 47.463 .989 \\
\hline Beban Transportasi & 25.043 .860 & 3.130 .483 & 3.130 .483 & 3.130 .483 & 3.130 .483 & 3.130 .483 & 3.130 .483 & 3.130 .483 & 3.130 .483 \\
\hline Beban Tes \& Pendidikan Keryawan & 104.875 .800 & 8.570 .375 & 12.470 .375 & 8.570 .375 & 30.820 .375 & 13.183 .575 & 9.533 .575 & 9.533 .575 & 12.193 .575 \\
\hline Beban Promosi & 302.656 .124 & 37.832 .015 & 37.832 .015 & 37.832 .015 & 37.832 .015 & 37.832 .015 & 37.832 .015 & 37.832 .015 & 37.832 .015 \\
\hline Beban ATK, Foto Copy & 131.196 .964 & 20.009 .142 & 11.682 .690 & 15.910 .635 & 11.708 .152 & 12.633 .254 & 13.565 .264 & 34.379 .273 & 11.308 .555 \\
\hline Beban Keperluan Kantor & 12.357 .630 & 1.261 .061 & 1.261 .061 & 3.211 .061 & 1.566 .061 & 1.261 .061 & 1.261 .061 & 1.275 .201 & 1.261 .061 \\
\hline Beban Rumah Tangga & 269.813 .729 & 18.737 .808 & 18.737 .808 & 24.258 .762 & 137.515 .073 & 17.641 .069 & 17.641 .069 & 17.641 .069 & 17.641 .069 \\
\hline Beban Perjalanan Dinas & 16.132 .933 & 2.100 .367 & 2.095 .367 & 2.050 .367 & 2.525 .367 & 1.845 .367 & 1.830 .367 & 1.830 .367 & 1.855 .367 \\
\hline Beban Perijinan \& Notaris & 29.921 .800 & 2.356 .250 & 2.356 .250 & 2.356 .250 & 2.556 .250 & 1.831 .250 & 2.431 .250 & 14.203 .050 & 1.831 .250 \\
\hline Beban Outsoursing & 549.946 .409 & 68.743 .301 & 68.743 .301 & 68.743 .301 & 68.743 .301 & 68.743 .301 & 68.743 .301 & 68.743 .301 & 68.743 .301 \\
\hline Beban Pemeliharaan & 258.976 .212 & 15.433 .312 & 15.433 .312 & 27.170 .328 & 148.693 .027 & 12.516 .558 & 14.516 .558 & 12.516 .558 & 12.696 .558 \\
\hline Beban Penyusutan & 2.304 .351 .106 & 151.922 .190 & 134.247 .779 & 374.822 .288 & 825.227 .696 & 128.911 .935 & 119.595 .641 & 354.457 .178 & 215.166 .400 \\
\hline Beban Asuransi & 32.297 .720 & 3.643 .494 & 3.643 .494 & 9.943 .038 & 6.793 .266 & 2.068 .608 & 2.068 .608 & 2.068 .608 & 2.068 .608 \\
\hline Beban Pajak & 59.681 .662 & 6.592 .095 & 6.592 .095 & 16.511 .895 & 12.001 .995 & 4.337 .145 & 4.337 .145 & 4.337 .145 & 4.972 .145 \\
\hline Beban Admin Bank & 200.540 .644 & 25.067 .581 & 25.067 .581 & 25.067 .581 & 25.067 .581 & 25.067 .581 & 25.067 .581 & 25.067 .581 & 25.067 .581 \\
\hline Beban Lain - lain & 186.331 .115 & 22.090 .427 & 22.923 .927 & 29.921 .627 & 22.692 .827 & 22.090 .427 & 22.431 .027 & 22.090 .427 & 22.090 .427 \\
\hline Total Beban Administrasi \& Umum & 9.366 .032 .760 & 1.111 .476 .940 & 884.246 .161 & 1.531.001.564 & 2.086 .035 .439 & 912.361 .722 & 838.153.891 & 1.105 .490 .736 & 897.266.307 \\
\hline
\end{tabular}

Sumber : Data Primer 
Dalam pemaparan Beban Administrasi dan Umum Rumah Sakit X tahun 2019 dan 2018 terdapat kolom besaran Beban Lain Lain. Beban Lain Lain tersebut didominasi oleh beban yang disebabkan oleh pemakaian TV Kabel dalam Unit Layanan di Rumah Sakit X dengan perbandingan sebagai berikut :

Primer

\begin{tabular}{|c|c|c|c|}
\hline \multicolumn{4}{|c|}{$\begin{array}{c}\text { TABEL } 6 \\
\text { PERHITUNGAN BEBAN LAIN LAIN } \\
\text { RUMAH SAKIT X TAHUN } 2019 \\
\end{array}$} \\
\hline Keterangan & $\begin{array}{c}\text { Total Beban } \\
\text { TV Kabel }\end{array}$ & $\begin{array}{c}\text { Beban } \\
\text { Lain - Lain }\end{array}$ & $\begin{array}{l}\text { Total Beban } \\
\text { Lain - Lain }\end{array}$ \\
\hline Rawat Jalan & 1.456 .545 & 1.919 .062 & 3.375 .608 \\
\hline IGD & 485.515 & 1.919 .062 & 2.404 .577 \\
\hline Rawat Inap & 26.703 .333 & 1.919 .062 & 28.622 .396 \\
\hline $\begin{array}{l}\text { Instalasi } \\
\text { Bedah }\end{array}$ & 1.456 .545 & 1.919 .062 & 3.375 .608 \\
\hline Farmasi & 485.515 & 1.919 .062 & 2.404 .577 \\
\hline Laboratorium & 485.515 & 1.919 .062 & 2.404 .577 \\
\hline Radiologi & 485.515 & 1.919 .062 & 2.404 .577 \\
\hline Rehab Medis & 485.515 & 1.919 .062 & 2.404 .577 \\
\hline TOTAL & 32.044.000 & 15.352 .498 & 47.396.498 \\
\hline
\end{tabular}

\begin{tabular}{lrcc}
\hline & \multicolumn{3}{c}{ TABEL 7 } \\
& $\begin{array}{c}\text { PERHITUNGAN BEBAN LAIN LAIN } \\
\text { RUMAH SAKIT X TAHUN 2018 }\end{array}$ \\
\hline \multicolumn{1}{c}{ Keterangan } & $\begin{array}{c}\text { Total Beban } \\
\text { TV Kabel }\end{array}$ & $\begin{array}{c}\text { Beban Lain - } \\
\text { Lain }\end{array}$ & $\begin{array}{l}\text { Total Beban } \\
\text { Lain - Lain }\end{array}$ \\
\hline Rawat jalan & 866.909 & 20.907 .389 & 21.774 .298 \\
\hline IGD & 288.970 & 20.907 .389 & 21.196 .359 \\
\hline Rawat Inap & 15.893 .333 & 20.907 .389 & 36.800 .723 \\
\hline $\begin{array}{l}\text { Instalasi } \\
\text { Bedah }\end{array}$ & 866.909 & 20.907 .389 & 21.774 .298 \\
\hline Farmasi & 288.970 & 20.907 .389 & 21.196 .359 \\
\hline $\begin{array}{l}\text { Laboratoriu } \\
\text { m }\end{array}$ & 288.970 & 20.907 .389 & 21.196 .359 \\
\hline Radiologi & 288.970 & 20.907 .389 & 21.196 .359 \\
\hline Rehab Medis & 288.970 & 20.907 .389 & 21.196 .359 \\
\hline TOTAL & $\mathbf{1 9 . 0 7 2 . 0 0 0}$ & $\mathbf{1 6 7 . 2 5 9 . 1 1 5}$ & $\mathbf{1 8 6 . 3 3 1 . 1 1 5}$ \\
\hline
\end{tabular}

Sumber : Data Primer 
Rahmawati \& Daengs: Implementasi Activity Based...

Adapun perbandingan metode pembebanan biaya pemakaian TV Kabel pada setiap Unit Layanan di Rumah Sakit X dengan menggunakan Metode pembebanan biaya Activity Based Costing dan pembebanan biaya yang dilakukan selama ini di Rumah Sakit X adalah sebagai berikut

\section{TABEL 8}

PERBANDINGAN PEMBEBANAN BIAYA PEMAKAIAN TV KABEL RUMAH SAKIT X PADA TAHUN 2019

\begin{tabular}{lcccccc}
\hline $\begin{array}{c}\text { Lokasi Unit } \\
\text { Layanan }\end{array}$ & $\begin{array}{c}\text { Jumlah } \\
\text { Titik }\end{array}$ & $\begin{array}{c}\text { Lama } \\
\text { Pemakaian }\end{array}$ & $\begin{array}{c}\text { Lama } \\
\text { Pemakaian } \\
\text { Per Tahun }\end{array}$ & $\begin{array}{c}\text { Pembebanan } \\
\text { Biaya Metode } \\
\text { ABC }\end{array}$ & $\begin{array}{c}\text { Pembebanan } \\
\text { Biaya di RS } \\
\text { X }\end{array}$ & Selisih \\
\hline Rawat Jalan & 1 & 12 jam & 372 & 1.456 .545 & 3.291 .643 & $(1.835 .097,07)$ \\
\hline IGD & 0,2 & $20 \mathrm{jam}$ & 124 & 485.515 & 3.291 .643 & $(2.806 .127,37)$ \\
\hline Rawat Inap & 11 & $20 \mathrm{jam}$ & 6820 & 26.703 .333 & 8.601 .727 & $18.101 .606,71$ \\
\hline Instalasi Bedah & 2 & $6 \mathrm{jam}$ & 372 & 1.456 .545 & 3.692 .418 & $(2.235 .872,77)$ \\
\hline Farmasi & 0,2 & $20 \mathrm{jam}$ & 124 & 485.515 & 3.291 .643 & $(2.806 .127,37)$ \\
\hline Laboratorium & 0,2 & $20 \mathrm{jam}$ & 124 & 485.515 & 3.291 .643 & $(2.806 .127,37)$ \\
\hline Radiologi & 0,2 & $20 \mathrm{jam}$ & 124 & 485.515 & 3.291 .643 & $(2.806 .127,37)$ \\
\hline Rehab Medis & 0,2 & $20 \mathrm{jam}$ & 124 & 485.515 & 3.291 .643 & $(2.806 .127,37)$ \\
\hline Total Tagihan & & & & 32.044 .000 & & \\
\hline
\end{tabular}

Sumber : Data Diolah (2019)

TABEL 9

PERBANDINGAN PEMBEBANAN BIAYA PEMAKAIAN TV KABEL RUMAH SAKIT X PADA TAHUN 2018

\begin{tabular}{lcccrrr}
\hline $\begin{array}{c}\text { Lokasi Unit } \\
\text { Layanan }\end{array}$ & $\begin{array}{c}\text { Jumlah } \\
\text { Titik }\end{array}$ & $\begin{array}{c}\text { Lama } \\
\text { Pemakaian }\end{array}$ & $\begin{array}{c}\text { Lama } \\
\text { Pemakaian } \\
\text { Per Tahun }\end{array}$ & $\begin{array}{c}\text { Pembebanan } \\
\text { Biaya Metode } \\
\text { ABC }\end{array}$ & $\begin{array}{c}\text { Pembebanan } \\
\text { Biaya di RS } \\
\text { X }\end{array}$ & Selisih \\
\hline Rawat Jalan & 1 & $12 \mathrm{jam}$ & 372 & 866.909 & 1.204 .800 & $(337.890,91)$ \\
\hline IGD & 0,2 & $20 \mathrm{jam}$ & 124 & 288.970 & 1.204 .800 & $(915.830,30)$ \\
\hline Rawat Inap & 11 & $20 \mathrm{jam}$ & 6820 & 15.893 .333 & 10.036 .000 & $5.857 .333,33$ \\
\hline Instalasi Bedah & 2 & $6 \mathrm{jam}$ & 372 & 866.909 & 1.807 .200 & $(940.290,91)$ \\
\hline Farmasi & 0,2 & $20 \mathrm{jam}$ & 124 & 288.970 & 1.204 .800 & $(915.830,30)$ \\
\hline Laboratorium & 0,2 & $20 \mathrm{jam}$ & 124 & 288.970 & 1.204 .800 & $(915.830,30)$ \\
\hline Radiologi & 0,2 & $20 \mathrm{jam}$ & 124 & 288.970 & 1.204 .800 & $(915.830,30)$ \\
\hline Rehab Medis & 0,2 & $20 \mathrm{jam}$ & 124 & 288.970 & 1.204 .800 & $(915.830,30)$ \\
\hline Total Tagihan & & & & 19.072 .000 & & \\
\hline \multicolumn{1}{c}{} \\
\hline
\end{tabular}

Sumber : Data Diolah (2018)

Data yang diperoleh dari bagian keuangan untuk tagihan TV kabel yang di keluarkan oleh Rumah Sakit X pada tahun 2019 adalah sebesar Rp. 32.044.000,- dan pada tahun 2018 sebesar Rp. 
19.072.000,- yang di bebankan pada setiap unit layanan penghasil. Maka dasar penentuan pemakaian TV kabel pada setiap unit didasarkan pada jumlah TV yang ada pada unit tersebut dikalikan dengan estimasi lama penggunaannya dalam sehari sehingga didapatkan pemakaian TV kabel adalah sebanyak 8184 jam selama satu tahun dengan biaya per jam Rp. 3.915 pada tahun 2019 dan Rp. 2.330 pada tahun 2018. Perhitungan pembebanan biaya TV Kabel pada setiap unit layanan dengan metode Activity Based Costing dihitung dengan rumus sebagai berikut :

Lama Pemakaian TV Kabel Tiap Unit Layanan

Total JamPemakaian TV Kabel selama 1 Tahun $x$ Jumlah Tagihan TV Kabel 1 Tahun

Dalam pemaparan Beban Administrasi dan Umum Rumah Sakit X tahun 2019 dan 2018 terdapat kolom besaran Beban Pajak. Beban Pajak tersebut yang dimaksud adalah pembebanan Beban Pajak Bumi dan Bangunan yang dibebankan pada bangunan Rumah Sakit X pada tahun 2019 dan 2018, perhitungannya adalah sebagai berikut :

\section{TABEL 10}

\section{PERHITUNGAN PBB RUMAH SAKT X TAHUN 2019}

\begin{tabular}{lccccrrr}
\hline Keterangan & Lantai & $\begin{array}{c}\text { Total } \\
\text { Ruangan }\end{array}$ & Luas & $\begin{array}{c}\text { Pembebanan } \\
\text { Biaya Metode } \\
\text { ABC }\end{array}$ & $\begin{array}{c}\text { Pembebanan } \\
\text { Biaya di RS X }\end{array}$ & Selisih \\
\hline Rawat Jalan & 1 & 4 & 100 & 5.184 .966 & 9.929 .932 & $(4.744 .966)$ \\
\hline IGD & 1 & 2 & 50 & 2.592 .483 & 9.929 .932 & $(7.337 .449)$ \\
\hline Farmasi & 1 & 2 & 50 & 2.592 .483 & 5.964 .965 & $(3.372 .482)$ \\
\hline Laboratorium & 1 & 2 & 50 & 2.592 .483 & 5.964 .965 & $(3.372 .482)$ \\
\hline Radiologi & 1 & 2 & 50 & 2.592 .483 & 5.964 .965 & $(3.372 .482)$ \\
\hline Rehab Medis & 1 & 4 & 100 & 5.184 .966 & 5.964 .965 & $(779.999)$ \\
\hline Ambulance & 1 & 1 & 25 & 1.296 .241 & & - & 1.296 .241 \\
\hline Marketing & 1 & 1 & 25 & 1.296 .241 & 1.654 .989 & $(358.748)$ \\
\hline Logistik & 1 & 1 & 25 & 1.296 .241 & 1.654 .989 & $(358.748)$ \\
\hline Pemeliharaan & 1 & 1 & 25 & 1.296 .241 & 1.654 .989 & $(358.748)$ \\
\hline Sub Total Lt. 1 & & $\mathbf{2 0}$ & $\mathbf{5 0 0}$ & $\mathbf{2 5 . 9 2 4 . 8 2 9}$ & $\mathbf{4 8 . 6 8 4 . 6 9 1}$ & $(\mathbf{2 2 . 7 5 9 . 8 6 2 )}$ \\
\hline Rawat Inap & 2 & 20 & 500 & 25.924 .829 & 29.789 .795 & $(3.864 .966)$ \\
\hline Sub Total Lt. 2 & & $\mathbf{2 0}$ & $\mathbf{5 0 0}$ & $\mathbf{2 5 . 9 2 4 . 8 2 9}$ & $\mathbf{2 9 . 7 8 9 . 7 9 5}$ & $\mathbf{( 3 . 8 6 4 . 9 6 6 )}$ \\
\hline Instalasi Bedah & 3 & 15 & 375 & 19.443 .622 & 20.259 .862 & $(816.240)$ \\
\hline SIRS & 3 & 5 & 125 & 6.481 .207 & 1.654 .989 & 4.826 .218 \\
\hline Sub Total Lt. 3 & & $\mathbf{2 0}$ & $\mathbf{5 0 0}$ & $\mathbf{2 5 . 9 2 4 . 8 2 9}$ & $\mathbf{2 1 . 9 1 4 . 8 5 1}$ & $\mathbf{4 . 0 0 9 . 9 7 8}$ \\
\hline Keungan & 4 & 4 & 100 & 5.184 .966 & 1.654 .989 & 3.529 .977 \\
\hline SDM & 4 & 4 & 100 & 5.184 .966 & 1.654 .989 & 3.529 .977 \\
\hline Direksi & 4 & 5 & 125 & 6.481 .207 & & - & 6.481 .207 \\
\hline SPI & 4 & 2 & 50 & 2.592 .483 & & 2.592 .483 \\
\hline
\end{tabular}


Rahmawati \& Daengs: Implementasi Activity Based...

\begin{tabular}{ccccrrr}
\hline Konsolidasi & 4 & 5 & 125 & 6.481 .207 & - & 6.481 .207 \\
\hline Sub Total Lt. 4 & & $\mathbf{2 0}$ & $\mathbf{5 0 0}$ & $\mathbf{2 5 . 9 2 4 . 8 2 9}$ & $\mathbf{3 . 3 0 9 . 9 7 8}$ & $\mathbf{2 2 . 6 1 4 . 8 5 1}$ \\
\hline TOTAL & & $\mathbf{8 0}$ & $\mathbf{2 0 0 0}$ & $\mathbf{1 0 3 . 6 9 9 . 3 1 5}$ & & \\
\hline
\end{tabular}

Sumber : Data Diolah (2019)

TABEL 11

PERHITUNGAN PBB RUMAH SAKT X TAHUN 2018

\begin{tabular}{|c|c|c|c|c|c|c|}
\hline Keterangan & Lantai & $\begin{array}{c}\text { Total } \\
\text { Ruangan }\end{array}$ & Luas & $\begin{array}{c}\text { Pembebanan } \\
\text { Biaya Metode } \\
\text { ABC } \\
\end{array}$ & $\begin{array}{c}\text { Pembebanan } \\
\text { Biaya di RS } \\
\text { X } \\
\end{array}$ & Selisih \\
\hline Rawat Jalan & 1 & 4 & 100 & 2.984 .083 & 6.707 .167 & $(3.723 .084)$ \\
\hline IGD & 1 & 2 & 50 & 1.492 .042 & 6.707 .167 & $(5.215 .125)$ \\
\hline Farmasi & 1 & 2 & 50 & 1.492 .042 & 3.053 .583 & $(1.561 .541)$ \\
\hline Laboratorium & 1 & 2 & 50 & 1.492 .042 & 3.053 .583 & $(1.561 .541)$ \\
\hline Radiologi & 1 & 2 & 50 & 1.492 .042 & 3.053 .583 & $(1.561 .541)$ \\
\hline Rehab Medis & 1 & 4 & 100 & 2.984 .083 & 3.053 .583 & $(69.500)$ \\
\hline Ambulance & 1 & 1 & 25 & 746.021 & - & 746.021 \\
\hline Marketing & 1 & 1 & 25 & 746.021 & 951.194 & $(205.173)$ \\
\hline Logistik & 1 & 1 & 25 & 746.021 & 951.194 & $(205.173)$ \\
\hline Pemeliharaan & 1 & 1 & 25 & 746.021 & 951.194 & (205.173) \\
\hline Sub Total Lt. 1 & & 20 & 500 & 14.920 .415 & 28.482 .248 & $(\mathbf{1 3 . 5 6 1 . 8 3 3 )}$ \\
\hline Rawat Inap & 2 & 20 & 500 & 14.920 .415 & 17.121 .498 & $(2.201 .083)$ \\
\hline Sub Total Lt. 2 & & 20 & 500 & 14.920 .415 & 17.121.498 & $(2.201 .083)$ \\
\hline Instalasi Bedah & 3 & 15 & 375 & 11.190 .312 & 11.224 .334 & $(34.022)$ \\
\hline SIRS & 3 & 5 & 125 & 3.730 .104 & 951.194 & 2.778 .910 \\
\hline Sub Total Lt. 3 & & 20 & 500 & 14.920 .415 & 12.175 .528 & 2.744 .887 \\
\hline Keungan & 4 & 4 & 100 & 2.984 .083 & 951.194 & 2.032 .889 \\
\hline SDM & 4 & 4 & 100 & 2.984 .083 & 951.194 & 2.032 .889 \\
\hline Direksi & 4 & 5 & 125 & 3.730 .104 & - & 3.730 .104 \\
\hline SPI & 4 & 2 & 50 & 1.492 .042 & - & 1.492 .042 \\
\hline Konsolidasi & 4 & 5 & 125 & 3.730 .104 & - & 3.730 .104 \\
\hline Sub Total Lt. 4 & & 20 & 500 & 14.920 .415 & 1.902 .388 & 13.018 .027 \\
\hline TOTAL & & 80 & 2000 & 59.681 .662 & & \\
\hline
\end{tabular}

Sumber : Data Diolah (2018)

Data yang diperoleh dari bagian keuangan untuk Pajak Bumi dan Bangunan yang di bayar oleh Rumah Sakit X pada tahun 2019 sebesar Rp. 103.699.315,- dan pada tahun 2018 sebesar Rp. 59.681.662,- yang di bebankan pada setiap unit layanan non penghasil maupun unit layanan penghasil. Dasar penentuan pembebanan Pajak Bumi dan Bangunan pada setiap unit layanan 
didasarkan luas ruangan disetiap unit layanan yang ada pada Rumah Sakit X dengan luasan total bangunan seluas $2000 \mathrm{~m}^{2}$. Dari total luas bangunan tersebut maka didapatkan biaya per meter sebesar Rp. 51.850,-pada tahun 2019 dan Rp. 29.841,- pada tahun 2018. Perhitungan pembebanan biaya Pajak Bumi dan Bangunan dengan metode Activity Based Costing pada setiap unit layanan dihitung dengan rumus sebagai berikut :

$$
\frac{\text { Luas Lantai Unit }}{\text { Total Luas Bangunan }} \times \text { Beban PBB } 1 \text { Tahun }
$$

Dalam pemaparan Beban Administrasi dan Umum Rumah Sakit X tahun 2019 dan 2018 terdapat kolom besaran Beban Asuransi. Beban Asuransi tersebut yang dimaksud adalah pembebanan Beban Asuransi Kebakaran yang dibebankan pada bangunan Rumah Sakit X pada tahun 2019 dan 2018, perhitungannya adalah sebagai berikut :

\begin{tabular}{|c|c|c|c|c|c|c|}
\hline \multicolumn{7}{|c|}{$\begin{array}{c}\text { TABEL } 12 \\
\text { PERHITUNGAN BEBAN ASURANSI KEBAKARAN R }\end{array}$} \\
\hline Keterangan & Lantai & $\begin{array}{c}\text { Total } \\
\text { Ruangan }\end{array}$ & Luas & $\begin{array}{l}\text { Pembebanan Biaya } \\
\text { Metode ABC }\end{array}$ & $\begin{array}{c}\text { Pembebanan } \\
\text { Biaya di RS X }\end{array}$ & Selisih \\
\hline Rawat Jalan & 1 & 4 & 100 & 1.260 .257 & 2.540 .515 & $(1.280 .258)$ \\
\hline IGD & 1 & 2 & 50 & 630.129 & 2.540 .515 & $(1.910 .386)$ \\
\hline Farmasi & 1 & 2 & 50 & 630.129 & 1.320 .257 & $(690.128)$ \\
\hline Laboratorium & 1 & 2 & 50 & 630.129 & 1.320 .257 & $(690.128)$ \\
\hline Radiologi & 1 & 2 & 50 & 630.129 & 1.320 .257 & (690.128) \\
\hline Rehab Medis & 1 & 4 & 100 & 1.260 .257 & 1.320 .257 & $\begin{array}{l}(60.000) \\
\end{array}$ \\
\hline Ambulance & 1 & 1 & 25 & 315.064 & - & 315.064 \\
\hline Marketing & 1 & 1 & 25 & 315.064 & 406.753 & $\begin{array}{l}(91.689) \\
\end{array}$ \\
\hline Logistik & 1 & 1 & 25 & 315.064 & 406.753 & $(91.689)$ \\
\hline Pemeliharaan & 1 & 1 & 25 & 315.064 & 406.753 & $\begin{array}{l}(91.689) \\
\end{array}$ \\
\hline Sub Total Lt. 1 & & 20 & 500 & 6.301 .287 & 11.582 .317 & $(5.281 .030)$ \\
\hline Rawat Inap & 2 & 20 & 500 & 6.301 .287 & 7.321 .545 & $(1.020 .258)$ \\
\hline Sub Total Lt. 2 & & 20 & 500 & 6.301 .287 & 7.321 .545 & $(\mathbf{1 . 0 2 0 . 2 5 8 )}$ \\
\hline Instalasi Bedah & 3 & 15 & 375 & 4.725 .966 & 5.081 .030 & $(355.064)$ \\
\hline SIRS & 3 & 5 & 125 & 1.575 .322 & 406.753 & 1.168 .569 \\
\hline Sub Total Lt. 3 & & 20 & 500 & 6.301 .287 & $\mathbf{5 . 4 8 7 . 7 8 3}$ & 813.504 \\
\hline Keungan & 4 & 4 & 100 & 1.260 .257 & 406.752 & 853.505 \\
\hline SDM & 4 & 4 & 100 & 1.260 .257 & 406.753 & 853.504 \\
\hline Direksi & 4 & 5 & 125 & 1.575 .322 & - & 1.575 .322 \\
\hline SPI & 4 & 2 & 50 & 630.129 & & 630.129 \\
\hline Konsolidasi & 4 & 5 & 125 & 1.575 .322 & - & 1.575 .322 \\
\hline
\end{tabular}


Rahmawati \& Daengs: Implementasi Activity Based...

\begin{tabular}{cccccc}
\hline Sub Total Lt. 4 & $\mathbf{2 0}$ & $\mathbf{5 0 0}$ & $\mathbf{6 . 3 0 1 . 2 8 7}$ & $\mathbf{8 1 3 . 5 0 5}$ & $\mathbf{5 . 4 8 7 . 7 8 2}$ \\
\hline TOTAL & $\mathbf{8 0}$ & $\mathbf{2 0 0 0}$ & $\mathbf{2 5 . 2 0 5 . 1 5 0}$ & & \\
\hline
\end{tabular}

Sumber : Data Diolah (2019)

\begin{tabular}{|c|c|c|c|c|c|c|}
\hline \multicolumn{7}{|c|}{$\begin{array}{c}\text { TABEL } 13 \\
\text { PERHITUNGAN BEBAN ASURANSI KEBAKARAN RUMAH SAKIT X TAHUN } 2018 \\
\end{array}$} \\
\hline Keterangan & Lantai & $\begin{array}{c}\text { Total } \\
\text { Ruangan }\end{array}$ & Luas & $\begin{array}{l}\text { Pembebanan Biaya } \\
\text { Metode ABC }\end{array}$ & $\begin{array}{c}\text { Pembebanan } \\
\text { Biaya di RS } \\
\text { X }\end{array}$ & Selisih \\
\hline Rawat Jalan & 1 & 4 & 100 & 1.614 .886 & 3.249 .772 & $(1.634 .886)$ \\
\hline IGD & 1 & 2 & 50 & 807.443 & 3.249 .772 & $(2.442 .329)$ \\
\hline Farmasi & 1 & 2 & 50 & 807.443 & 1.674 .886 & (867.443) \\
\hline Laboratorium & 1 & 2 & 50 & 807.443 & 1.674 .886 & (867.443) \\
\hline Radiologi & 1 & 2 & 50 & 807.443 & 1.674 .886 & $(867.443)$ \\
\hline Rehab Medis & 1 & 4 & 100 & 1.614 .886 & 1.674 .886 & (60.000) \\
\hline Ambulance & 1 & 1 & 25 & 403.722 & - & 403.722 \\
\hline Marketing & 1 & 1 & 25 & 403.722 & 524.962 & $(121.241)$ \\
\hline Logistik & 1 & 1 & 25 & 403.722 & 524.962 & $(121.241)$ \\
\hline Pemeliharaan & 1 & 1 & 25 & 403.722 & 524.962 & $(121.241)$ \\
\hline Sub Total Lt. 1 & & 20 & 500 & 8.074 .430 & 14.773 .974 & $(6.699 .544)$ \\
\hline Rawat Inap & 2 & 20 & 500 & 8.074 .430 & 9.449 .316 & $(1.374 .886)$ \\
\hline Sub Total Lt. 2 & & 20 & 500 & 8.074 .430 & 9.449 .316 & $(1.374 .886)$ \\
\hline Instalasi Bedah & 3 & 15 & 375 & 6.055 .823 & 6.299 .544 & $(243.722)$ \\
\hline SIRS & 3 & 5 & 125 & 2.018 .608 & 524.962 & 1.493 .646 \\
\hline Sub Total Lt. 3 & & 20 & 500 & 8.074 .430 & 6.824 .506 & 1.249 .924 \\
\hline Keungan & 4 & 4 & 100 & 1.614 .886 & 624.962 & 989.924 \\
\hline SDM & 4 & 4 & 100 & 1.614 .886 & 624.962 & 989.924 \\
\hline Direksi & 4 & 5 & 125 & 2.018 .608 & - & 2.018 .608 \\
\hline SPI & 4 & 2 & 50 & 807.443 & & 807.443 \\
\hline Konsolidasi & 4 & 5 & 125 & 2.018 .608 & - & 2.018 .608 \\
\hline Sub Total Lt. 4 & & 20 & 500 & 8.074 .430 & 1.249 .924 & 6.824 .506 \\
\hline TOTAL & & 80 & 2000 & 32.297 .720 & & \\
\hline
\end{tabular}

Sumber : Data Diolah (2018)

Data yang diperoleh dari bagian keuangan untuk Beban Asuransi yang di bayar oleh Rumah Sakit X pada tahun 2019 sebesar Rp. 25.205.150,- dan pada tahun 2018 sebesar Rp. 32.297.720,- yang di bebankan pada setiap unit layanan non penghasil maupun penghasil. Dasar penentuan pembebanan Beban Asuransi pada setiap unit layanan didasarkan luas 
ruangan disetiap unit layanan yang ada pada Rumah Sakit X dengan luasan total bangunan seluas $2000 \mathrm{~m}^{2}$. Dari total luas bangunan tersebut maka didapatkan biaya per meter sebesar Rp. 12.603,-pada tahun 2019 dan Rp. 16.149,-- pada tahun 2018. Perhitungan pembebanan biaya asuransi dengan metode Activity Based Costing pada setiap unit layanan dihitung dengan rumus sebagai berikut :

$$
\frac{\text { Luas Lantai Unit }}{\text { Total Luas Bangunan }} \times \text { Beban Asuransi } 1 \text { Tahun }
$$

Dalam pemaparan Beban Administrasi dan Umum Rumah Sakit X tahun 2019 dan 2018 terdapat kolom besaran Beban Penyusutan. Beban Penyusutan tersebut terdiri dari beban penyusutan bangunan dan beban penyusutan peralatan medis. Besaran nilai beban penyusutan pada tahun 2019 dan tahun 2018 didominasi oleh beban penyusutan bangunan yaitu sebesar Rp. 2.137.186.496 dari total beban penyusutan sebesar Rp. 3.696. 045.996 di tahun 2019 dan sebesar Rp. 1.111.833.614 dari total beban penyusutan sebesar Rp. 2.304.351.106 di tahun 2018. Adapun perbandingan pembebanan perhitungan beban penyusutan bangunan yang dilaksanakan di Rumah Sakit X dan perhitungan beban penyusutan dengan menggunakan Metode Activity Based Costing adalah sebagai berikut :

\begin{tabular}{|c|c|c|c|c|c|c|}
\hline PERHITUNC & AN BEB & AN PENYI & JSUTA & $\begin{array}{l}\text { ABEL 14 } \\
\text { J BANGUNAN }\end{array}$ & UMAH SAKIT X & AHUN 2019 \\
\hline Keterangan & Lantai & $\begin{array}{c}\text { Total } \\
\text { Ruangan }\end{array}$ & Luas & $\begin{array}{c}\text { Pembebanan } \\
\text { Biaya Metode } \\
\text { ABC }\end{array}$ & $\begin{array}{l}\text { Pembebanan } \\
\text { Biaya di RS X }\end{array}$ & Selisih \\
\hline Rawat Jalan & 1 & 4 & 100 & 106.859 .325 & 108.267 .545 & $(1.408 .220)$ \\
\hline IGD & 1 & 2 & 50 & 53.429 .662 & 43.859 .102 & 9.570 .560 \\
\hline Farmasi & 1 & 2 & 50 & 53.429 .662 & 60.649 .829 & (7.220.167) \\
\hline Laboratorium & 1 & 2 & 50 & 53.429 .662 & 46.267 .545 & 7.162 .117 \\
\hline Radiologi & 1 & 2 & 50 & 53.429 .662 & 28.042 .216 & 25.387 .446 \\
\hline Rehab Medis & 1 & 4 & 100 & 106.859 .325 & 46.267 .545 & 60.591 .780 \\
\hline Ambulance & 1 & 1 & 25 & 26.714 .831 & 21.225 .329 & $\overline{5.489 .502}$ \\
\hline Marketing & 1 & 1 & 25 & 26.714 .831 & 191.304 .432 & $(164.589 .601)$ \\
\hline Logistik & 1 & 1 & 25 & 26.714 .831 & 25.030 .937 & 1.683 .894 \\
\hline Pemeliharaan & 1 & 1 & 25 & 26.714 .831 & 108.096 .999 & $(81.382 .168)$ \\
\hline Sub Total Lt. 1 & & 20 & 500 & 534.296 .624 & 679.011.479 & $(144.714 .855)$ \\
\hline Rawat Inap & 2 & 20 & 500 & 534.296 .624 & 253.154 .613 & 281.142 .011 \\
\hline
\end{tabular}


Rahmawati \& Daengs: Implementasi Activity Based...

\begin{tabular}{|c|c|c|c|c|c|c|}
\hline Sub Total Lt. 2 & & 20 & 500 & 534.296 .624 & 253.154 .613 & 281.142 .011 \\
\hline $\begin{array}{l}\text { Instalasi } \\
\text { Bedah }\end{array}$ & 3 & 15 & 375 & 400.722 .468 & 282.257 .305 & 118.465 .163 \\
\hline SIRS & 3 & 5 & 125 & 133.574 .156 & 39.351 .733 & 94.222 .423 \\
\hline Sub Total Lt. 3 & & 20 & 500 & 534.296 .624 & 321.609 .038 & 212.687 .586 \\
\hline Keuangan & 4 & 5 & 100 & 106.859 .325 & 25.615 .851 & 81.243 .474 \\
\hline SDM & 4 & 5 & 100 & 106.859 .325 & 4.671 .843 & 102.187 .482 \\
\hline Direksi & 4 & 5 & 125 & 133.574 .156 & 424.517 .836 & $(290.943 .680)$ \\
\hline SPI & 4 & 2 & 50 & 53.429 .662 & 2.042 .780 & 51.386 .882 \\
\hline Konsolidasi & 4 & 5 & 125 & 133.574 .156 & 426.563 .056 & $(292.988 .900)$ \\
\hline Sub Total Lt. 4 & & 22 & 500 & 534.296 .624 & 883.411.366 & $(349.114 .742)$ \\
\hline TOTAL & & 82 & 2000 & 2.137.186.496 & & \\
\hline
\end{tabular}

Sumber : Data Diolah (2019)

\section{TABEL 15}

PERHITUNGAN BEBAN PENYUSUTAN BANGUNAN RUMAH SAKIT X TAHUN 2018

\begin{tabular}{lcccrrr}
\hline Keterangan & Lantai & $\begin{array}{c}\text { Total } \\
\text { Ruangan }\end{array}$ & Luas & $\begin{array}{c}\text { Pembebanan } \\
\text { Biaya Metode } \\
\text { ABC }\end{array}$ & $\begin{array}{c}\text { Pembebanan } \\
\text { Biaya di RS X }\end{array}$ & Selisih \\
\hline Rawat Jalan & 1 & 4 & 100 & 55.591 .681 & 30.563 .341 & 25.028 .340 \\
\hline IGD & 1 & 2 & 50 & 27.795 .840 & 25.867 .924 & 1.927 .916 \\
\hline Farmasi & 1 & 2 & 50 & 27.795 .840 & 34.314 .593 & $(6.518 .753)$ \\
\hline Laboratorium & 1 & 2 & 50 & 27.795 .840 & 30.563 .341 & $(2.767 .501)$ \\
\hline Radiologi & 1 & 2 & 50 & 27.795 .840 & 18.477 .088 & 9.318 .752 \\
\hline Rehab Medis & 1 & 4 & 100 & 55.591 .681 & 30.563 .341 & 25.028 .340 \\
\hline Ambulance & 1 & 1 & 25 & 13.897 .920 & 11.086 .253 & 2.811 .667 \\
\hline Marketing & 1 & 1 & 25 & 13.897 .920 & 36.954 .177 & $(23.056 .257)$ \\
\hline Logistik & 1 & 1 & 25 & 13.897 .920 & 25.867 .924 & $(11.970 .004)$ \\
\hline Pemeliharaan & 1 & 1 & 25 & 13.897 .920 & 164.370 .037 & $(150.472 .117)$ \\
\hline Sub Total Lt. 1 & & $\mathbf{2 0}$ & $\mathbf{5 0 0}$ & $\mathbf{2 7 7 . 9 5 8 . 4 0 4}$ & $\mathbf{4 0 8 . 6 2 8 . 0 1 9}$ & $\mathbf{( 1 3 0 . 6 6 9 . 6 1 6 )}$ \\
\hline Rawat Inap & 2 & 20 & 500 & 277.958 .404 & 180.207 .542 & 97.750 .862 \\
\hline Sub Total Lt. 2 & & $\mathbf{2 0}$ & $\mathbf{5 0 0}$ & $\mathbf{2 7 7 . 9 5 8 . 4 0 4}$ & $\mathbf{1 8 0 . 2 0 7 . 5 4 2}$ & $\mathbf{9 7 . 7 5 0 . 8 6 2}$ \\
\hline Instalasi Bedah & 3 & 15 & 375 & 208.468 .803 & 286.658 .827 & $(78.190 .024)$ \\
\hline SIRS & 3 & 5 & 125 & 69.489 .601 & 44.177 .511 & 25.312 .090 \\
\hline Sub Total Lt. 3 & & $\mathbf{2 0}$ & $\mathbf{5 0 0}$ & $\mathbf{2 7 7 . 9 5 8 . 4 0 4}$ & $\mathbf{3 3 0 . 8 3 6 . 3 3 8}$ & $\mathbf{( 5 2 . 8 7 7 . 9 3 5 )}$ \\
\hline Keuangan & 4 & 5 & 100 & 55.591 .681 & 25.867 .920 & 29.723 .761 \\
\hline
\end{tabular}


Jurnal Riset Akuntansi Aksioma

Vol. 20, No. 1, Juni 2021

\begin{tabular}{llccrrr}
\hline SDM & 4 & 5 & 100 & 55.591 .681 & 3.695 .418 & 51.896 .263 \\
\hline Direksi & 4 & 5 & 125 & 69.489 .601 & 3.695 .418 & 65.794 .183 \\
\hline SPI & 4 & 2 & 50 & 27.795 .840 & - & 27.795 .840 \\
\hline Konsolidasi & 4 & 5 & 125 & 69.489 .601 & 158.902 .959 & $(89.413 .358)$ \\
\hline Sub Total Lt. 4 & & $\mathbf{2 2}$ & $\mathbf{5 0 0}$ & $\mathbf{2 7 7 . 9 5 8 . 4 0 4}$ & $\mathbf{1 9 2 . 1 6 1 . 7 1 5}$ & $\mathbf{8 5 . 7 9 6 . 6 8 9}$ \\
\hline \multicolumn{1}{c}{ TOTAL } & & $\mathbf{8 2}$ & $\mathbf{2 0 0 0}$ & $\mathbf{1 . 1 1 1 . 8 3 3 . 6 1 4}$ & & \\
\hline
\end{tabular}

Sumber : Data Diolah (2018)

Perhitungan pembebanan biaya beban penyusutan bangunan pada setiap unit layanan dengan metode Activity Based Costing dihitung dengan rumus sebagai berikut :

$$
\frac{\text { Luas Lantai Unit }}{\text { Total Luas Bangunan }} \text { x Biaya Penyusutan Bangunan selama } 1 \text { Tahun }
$$

Dari paparan perhitungan beban operasional Rumah Sakit X diatas, dapat dilihat bahwa penggunaan metode Activity Based Costing dapat memberikan hasil perhitungan besaran beban operasional yang lebih akurat, karena perhitungan beban operasional dengan Activity Based Costing bertumpu pada dasar pembebanan besaran beban operasional yang lebih akurat pada setiap unit layanan Rumah Sakit X. Dimana perhitungan beban operasional pada setiap unit layanan di Rumah Sakit X dilakukan dengan cara membagi besaran beban operasional pada setiap unit dengan total beban operasional kemudian dikalikan dengan beban operasional selama satu tahun untuk setiap jenis beban operasional.

\section{SIMPULAN}

Hasil analisa implementasi perhitungan tersebut mendukung paparan penelitian terdahulu yang dilakukan oleh Waladouw (2014) dan Puspita (2014) bahwa metode Activity Based Costing dapat menjadi alat yang akurat dalam memperhitungkan besaran beban operasional yang didasarkan pada ukuran aktivitas pada masing masing unit layanan sehingga perhitungan tersebut dapat dipergunakan untuk menyusun laporan keuangan dengan nilai yang wajar serta dapat berguna sebagai dasar untuk perhitungan dalam rangka menentukan tarif layanan yang diberikan pada Rumah Sakit X.

Penelitian ini memiliki keterbatasan dalam hal detail data yang bisa didapatkan untuk membuat rincian perhitungan besaran beban operasional dengan metode Activity Based Costing sampai dengan menjadi laporan keuangan secara utuh. Penelitian selanjutnya diharapkan mampu untuk dapat mengaplikasikan metode Activity Based Costing dalam perhitungan besaran beban operasionalnya sampai dengan tersusunnya laporan keuangan utuh, sehingga dapat memberikan runtutan utuh dari penerapan metode Activity Based Costing mulai dari pembebanan besaran biaya operasional, penyusunan laporan keuangan yang didasarkan pada metode tersebut sampai dengan penetapan tarif layanan yang didasarkan pada Activity Based Costing.

\section{DAFTAR PUSTAKA}

Anwar, S., \& Barus, M. I. J. A.-M. J. I.-I. S. d. K. (2019). Perhitungan Unit Cost Pembiayaan Pendidikan Program Studi PAI STAI Sepakat Segenep Kutacane Metode Activity Based Costing. 4(1), 136-145. 
Rahmawati \& Daengs: Implementasi Activity Based...

Banker, R. D., \& Byzalov, D. J. J. o. M. A. R. (2014). Asymmetric cost behavior. 26(2), 43-79.

Caroline, T. C., \& Wokas, H. R. J. J. E. J. R. E., Manajemen, Bisnis dan Akuntansi. (2016). Analisis Penerapan Target Costing dan Activity-Based Costing sebagai Alat Bantu Manajemen dalam Pengendalian Biaya Produksi pada UD. Bogor Bakery. 4(1).

Damayanti, R. A., Murwani, J., \& Utomo, S. W. (2017). Analisis Penerapan Metode Activity Based Costing Dalam Penentuan Tarif Harga Sewa Kamar Hotel. Paper presented at the FIPA: Forum Ilmiah Pendidikan Akuntansi.

Gunawan, I. J. J. B. A. (2013). Metode penelitian kualitatif. 143.

Harmana, I. M. D. J. J. o. P., \& Accounting, B. (2020). Penerapan Metode Activity Based Costing System Dalam Menentukan Tarif Rawat Inap. 1(2), 54-63.

Kapojos, R., Sondakh, J. J., \& Waladouw, S. J. J. E. J. R. E., Manajemen, Bisnis dan Akuntansi. (2014). Penerapan Metode Activity Based Costing Dalam Penentuan Harga Pokok Produksi Pada Perusahaan Roti Lidya Manado. 2(2).

Natalia, D. N., Mendur, F., Sarayar, C. J. J. O. C., \& Emergency. (2016). Hubungan Kualitas Pelayanan Kesehatan dengan Kepuasan Pasien Rawat Inap di Rumah Sakit Medical Center Paal 2 Kota Manado. 4(1), 79-79.

Panekenan, I., \& Sabijono, H. J. J. E. J. R. E., Manajemen, Bisnis dan Akuntansi. (2014). Penerapan Metode Activity Based Costing Dalam Menentukan Besarnya Tarif Jasa Inap Pada Penginapan Vili Calaca Manado. 2(2).

Pawiyataningrum, A. N. J. J. A. B. (2014). Penerapan Activity Based Costing (ABC) Systemuntuk Menentukan Harga Pokok Produksi (Studi Pada PT. Indonesia Pet Bottle Pandaan Pasuruan). 10(1).

Rotikan, G. S. J. J. E. J. R. E., Manajemen, Bisnis dan Akuntansi. (2013). Penerapan metode activity based costing dalam penentuan harga pokok produksi pada PT. Tropica Cocoprima. 1(3).

Sendari, A. A. (2019). Mengenal Jenis Penelitian Deskriptif Kualitatif pada Sebuah Tulisan Ilmiah. Retrieved from https://hot.liputan6.com/read/4032771/mengenal-jenis-penelitiandeskriptif-kualitatif-pada-sebuah-tulisan-ilmiah

Weiss, D. J. T. A. R. (2010). Cost behavior and analysts' earnings forecasts. 85(4), 1441-1471.

Yemimaria, Y., Utary, A. R., \& Subhan, M. J. A. (2018). Analisis penerapan metode activity based costing dalam menentukan besarnya tarif jasa rawat inap. 15(1), 29-38. 